\title{
Novel 1,3-dichalcogeno-2-phospholanes with an annelated 1,2-dicarba-closo-dodecaborane(12) Unit
}

\author{
By Bernd Wrackmeyer* \\ Elena V. Klimkina ${ }^{\dagger}$ \\ Wolfgang Milius ${ }^{t}$
}

\begin{abstract}
The most efficient strategies for the synthesis of novel 1,3dichalcogeno-2-phospholanes (chalcogen $E=O, S, S e, T e$ ) are introduced, starting from 1,2-dicarba-closo-dodecaborane(12) ("ortho-carborane"), its 1,2-di-lithiated derivative, and various phosphorus halides. The annelation of the phospholane ring with the rigid three-dimensional carborane framework causes markedly different properties when compared with other phospholanes. Most noteworthy are the structural alternatives concerning the orientation of the lone pair of electrons at phosphorus, the instability of $P$ halides in particular for $E=O$, and the pronounced tendency for dimerization in the case of P-organo derivatives, which increases from $E=T e<S e<S<<O$. The latter is a consequence of spatial proximity between $P-R$ or electron density at phosphorus and the carborane skeleton. Direct structural evidence is provided for monomers and dimers by single crystal X-ray structural analysis. The solution-state structures follow from consistent sets of multinuclear magnetic resonance data $\left({ }^{1} \mathrm{H},{ }^{11} \mathrm{~B},{ }^{13} \mathrm{C},{ }^{31} \mathrm{P},{ }^{77} \mathrm{Se},{ }^{125} \mathrm{Te}\right.$ NMR). This is complemented by calculations leading to optimized gas-phase geometries at the B3LYP/6-311+G(d,p) level of theory. Most NMR parameters (chemical shifts $\delta$ and indirect nuclear spinspin coupling constants $\left.{ }^{n} \mathrm{~J}\right)$ are calculated at the same level of theory. These studies indicate that there are cases, for which important features of the solid-state structures may not be retained in solution.
\end{abstract}

\section{Introduction}

1,3-Dichalcogeno-2-phospholanes have been known for some time, in particular the 1,3-dioxa- (Arbuzov, 1948; Lucas, 1950; Burg, 1961; Fontal, 1966) and less so the 1,3-dithia derivatives (Arbuzov, 1952; Wieber, 1964; Peake, 1972; Albrand, 1973), by contrast to rare examples for 1,3-diselena-

\footnotetext{
*Professor, Anorganische Chemie II, Universität Bayreuth, Germany.

${ }^{\dagger}$ Anorganische Chemie II, Universität Bayreuth, Germany.

* Anorganische Chemie I, Universität Bayreuth, Germany.
} 
(Ogawa, 1995) and non-existent 1,3-ditellura compounds. These cyclic phosphines differ in many respects from their six-membered or non-cyclic counterparts. The carbon backbone frequently consists of the $\mathrm{CH}_{2}-\mathrm{CH}_{2}$ moiety (A) or is a benzo group (B). The typical structures, of which many have been determined by X-ray analysis, are presented in Fig. 1. Usually one finds an envelope structure with the phosphorus atom in the flap and the substituent at phosphorus in the axial position, leaving the equatorial space for the lone pair of electrons. In the solid state, the $\mathrm{CH}_{2}$ units may be arranged as in $\mathbf{A}$ or twisted against each other $\left(\mathbf{A}^{\prime}\right)$, to escape the maximum of steric repulsion exerted by the substituent at phosphorus. The latter alternative is unnecessary in the case of the benzo derivatives (B). A rigid three-dimensional unit instead of the $\mathrm{CH}_{2}-$ $\mathrm{CH}_{2}$ - or the benzo group could change the principal structure (see D as compared with $\mathbf{C}$ ) and by this the properties of such compounds. Therefore, we have set out to synthesize and investigate 1,3-dichalcogeno-2-phospholanes with an annelated 1,2-dicarba-closo-dodecaborane(12) unit ( $\mathbf{C}$ and/or $\mathbf{D})$.

Figure 1. Principal structures of 1,3-dichalcogeno-2-phospholanes $(E=O, S$, $\mathrm{Se}, \mathrm{Te}$ )<smiles>PP1PC2CCC21</smiles>

A

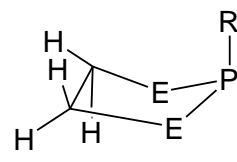

$A^{\prime}$

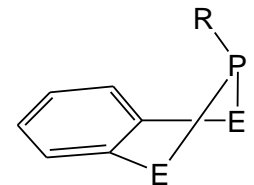

B

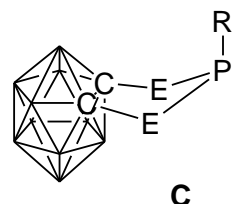

C

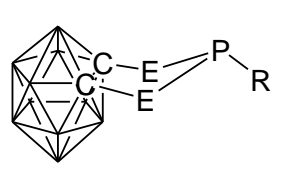

D

The chemistry of 1,2-dicarba-closo-dodecaborane(12) 1 (so called "orthocarborane") in general is well developed (Grimes, 2011; Bregadze, 1992). One important step for derivatization involves di-lithiation (2), and for our purposes insertion of sulfur (Smith, 1966; Herberhold, 1999; Popescu, 2012), selenium (Herberhold, 1999; Jin, 2004) or tellurium (Herberhold, 1999; Wrackmeyer, 2013, 398-408) into the C-Li bonds (3). The oxygen derivatives 4 (Ohta, 2007) and 5 have to be prepared by a different route, and the silanes 6 (Wrackmeyer, 2010; Wrackmeyer, 2014, Dalton Trans.) turned out to be particularly useful for further transformations. Scheme 1 shows the information on starting materials which can be used in reactions with phosphorus halides to obtain the desired novel 1,3-dichalcogeno-2-phospholanes.

NMR spectroscopy $\left({ }^{1} \mathrm{H},{ }^{13} \mathrm{C},{ }^{11} \mathrm{~B},{ }^{29} \mathrm{Si},{ }^{31} \mathrm{P},{ }^{77} \mathrm{Se}\right.$ and $\left.{ }^{125} \mathrm{Te} \mathrm{NMR}\right)$ is the major analytical tool for the assessment of solution-state structures. These measurements are accompanied by quantum-chemical analyses aiming for optimization [B3LYP/6-311+G(d,p) level of theory (Becke, 1993; Lee, 1988, Stevens, 1994, McLean, 1980; Krishnan, 1980)] of gas-phase structures and calculation of NMR parameters [chemical shifts $\delta \mathrm{X}\left(\mathrm{X}={ }^{11} \mathrm{~B},{ }^{13} \mathrm{C},{ }^{31} \mathrm{P},{ }^{99} \mathrm{Se}\right)$ (Wollinski, 1990) and indirect nuclear spin-spin coupling constants ${ }^{\mathrm{n}} J(\mathrm{~A}, \mathrm{X})$ (Helgaker, 2008; Contreras, 2003)]. 
Scheme 1. The most useful starting materials for reactions with phosphorus halides

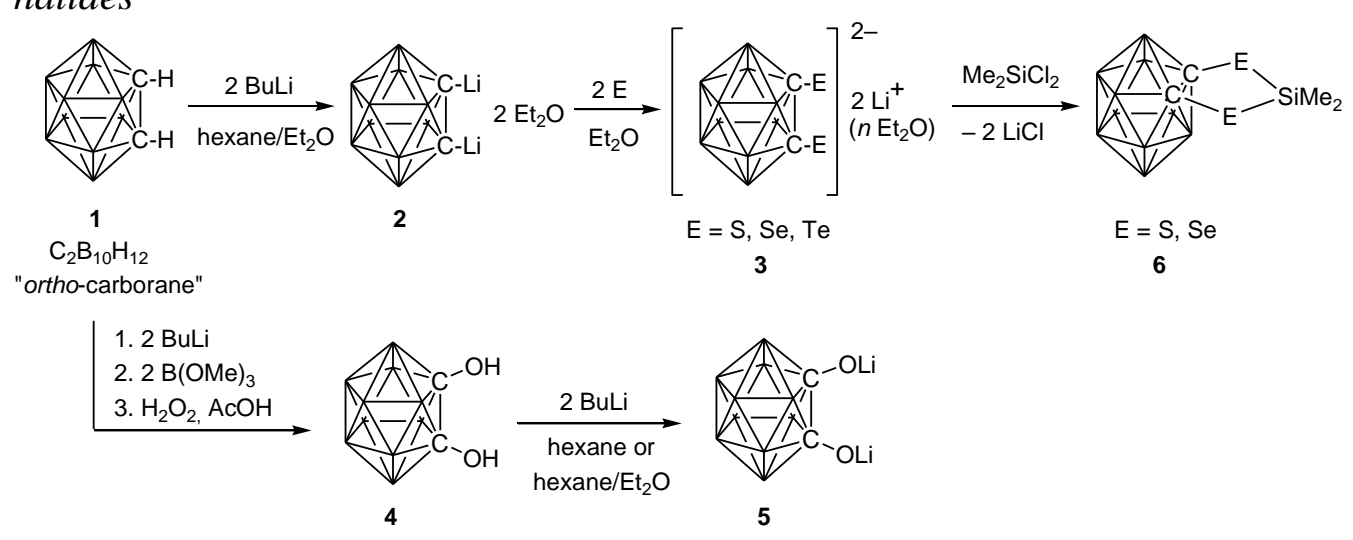

\section{Results \& Discussion}

1,3-Dioxa-2-phospholanes with an annelated 1,2-dicarba-closododecaborane (12) Unit

Scheme 2 shows that the phosphorus halides 7 are formed as expected. However, after short time in the reaction solutions or in the course of work-up procedures disproportionation reactions towards phosphite derivatives $\mathbf{8}$ take place (Wrackmeyer, 2014, 233-246). Apparently, the phosphorus halides 7 are less stable than comparable halides of the type $\mathbf{A}$ or $\mathbf{B}(E=O$; Fig. 1) some of which are commercially available. So far neither the parent phosphine compound with a $\mathrm{P}-\mathrm{H}$ unit nor the fluoride has been obtained. According to calculated gas-phase structures, solely the unavailable parent phosphine adopts the structure $\mathbf{C}$, and all others prefer structure $\mathbf{D}(\mathrm{E}=\mathrm{O}$; Fig. 1) (Wrackmeyer, 2014, 233-246).

Scheme 2. Synthesis and major way of decomposition of 2-halogeno-1,3dioxa-2-phospholanes

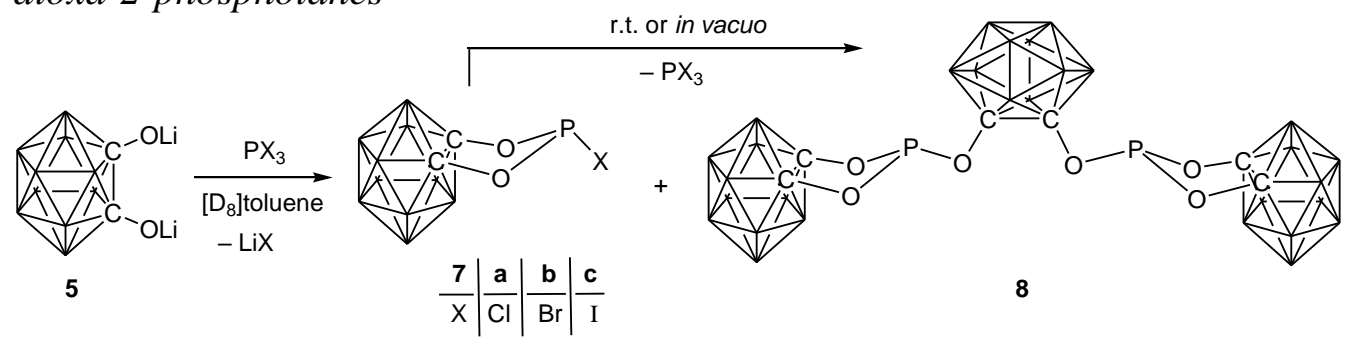

All monomer P-organo derivatives 9a-d and even the P-ethoxy- (9e) and P-diethylamino derivative (9f) tend to dimerize within hours or days (Wrackmeyer, 2014, 233-246). Again this is in contrast to A or B (E = O; Fig. 1) which dimerize very slowly or not at all (Dutasta, 1980; Pudovik, 1983). Figure 2 shows the molecular structure of the dimer 10c, as determined by Xray analysis. In the ten-membered ring the four oxygen atoms are in one plane 
(mean deviation $1.9 \mathrm{pm}$ ), and both phosphorus atoms are shifted out of this plane $(88.8 \mathrm{pm}, 88.5 \mathrm{pm})$.

Scheme 3. Synthesis and dimerization of 2-R-1,3-dioxa-2-phospholanes
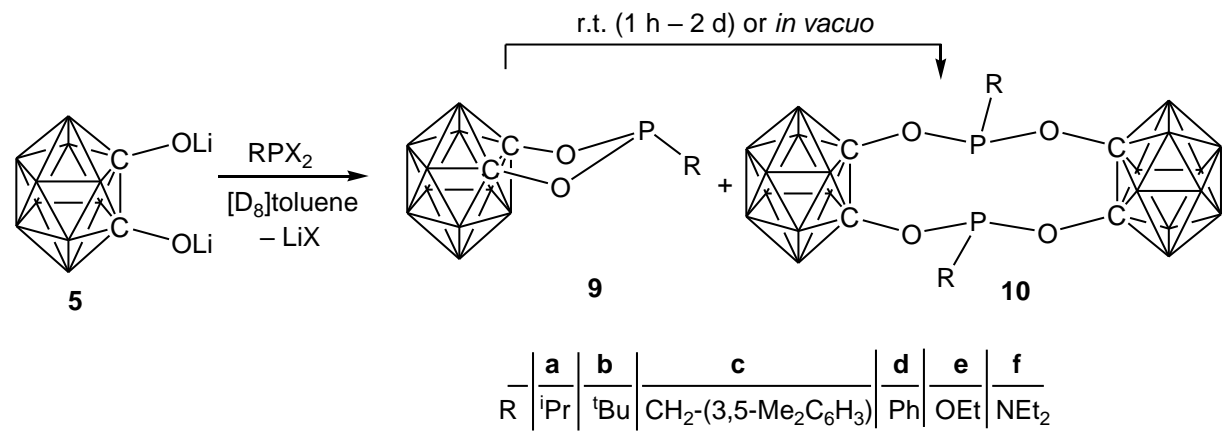

Figure 2. ORTEP plot (50\% probability; hydrogen atoms are omitted for clarity) of the molecular structure of dimer 10c. Selected bond lengths (pm) and angles $\left({ }^{\circ}\right)$ : C1-C2 171.7(5), C3-C4 169.7(5), C1-O1 136.9(5), P1-O1 167.0(2), P1-C5 190.9(4); O1-P1-O2 95.24(12),C2-C1-O1 116.4(3).

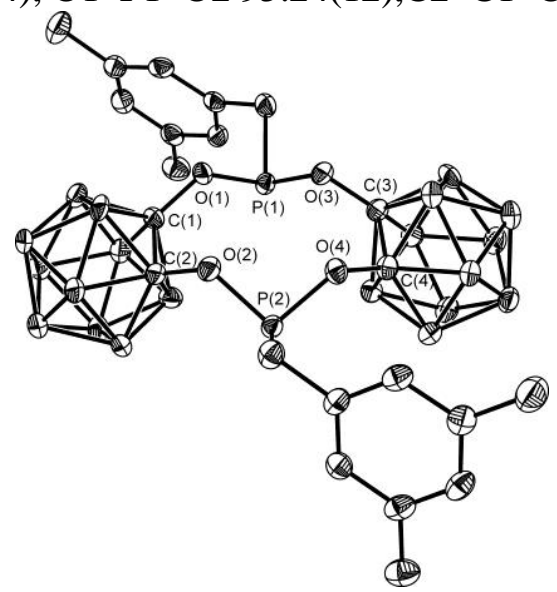

${ }^{31} \mathrm{P}$ NMR spectra show significant deshielding of the ${ }^{31} \mathrm{P}$ nuclei in the fivemembered rings relative to those in the dimers. This mirrors partly the ring strain together with repulsive effects in the small rings. The structural assignments for the solution-state of monomers and dimers are strongly supported by a linear correlation between calculated [given for the shortcomings of the theoretical approach (van Wüllen, 2000)] and experimental $\delta^{31} \mathrm{P}$ values.

The annelated carborane skeleton destabilizes monomeric 1,3-dioxa-2phospholanes. Any gain in kinetical staibilization is more than counterbalanced by steric repulsion between the carborane skeleton and the lone pair of electrons at phosphorus in axial position. According to calculations, solely the hydrogen atom is tolerated in axial position, and all other substituents are forced into the equatorial position to avoid close contacts with the rigid carborane skeleton. 
1,3-Dithia- and 1,3-diselena-2-phospholanes with an annelated 1,2-dicarbacloso-dodecaborane (12) Unit

The best synthetic strategy starts from the silanes 6 (Scheme 4) (Wrackmeyer, 2012; Wrackmeyer, 2014, 1929-1948), although the di-lithium salts $3(E=S, S e)$ can also be used (Wrackmeyer, 2007; Wrackmeyer, 2014, Dalton Trans.). However, the reactions of the silanes $\mathbf{6}$ with phosphorus halides afford the products in higher purity and much better yield.

Scheme 4. General synthesis of 1,3-dithia- and 1,3-diselena-2-phospholanes

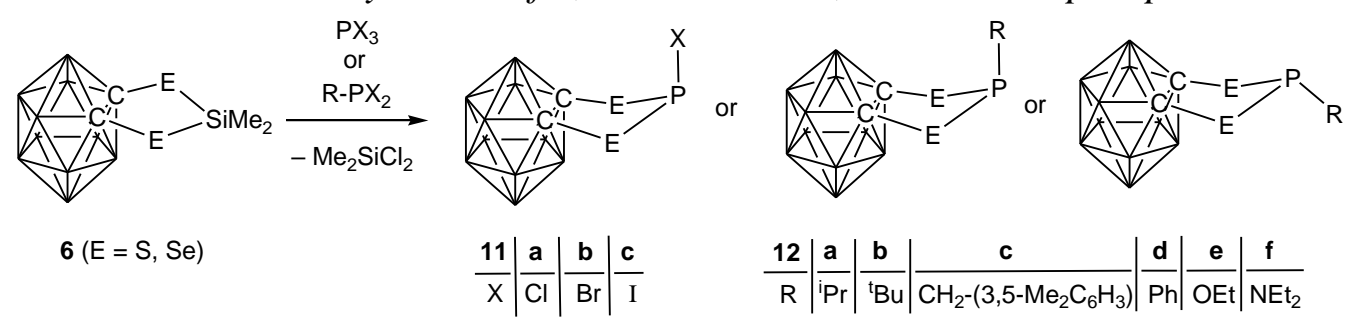

The phosphorus halides $\mathbf{1 1}$ are more stable than their oxygen analogues $\mathbf{7}$, since the disproportionation products analogous to $\mathbf{8}$ play a minor role for $\mathrm{X}=$ $\mathrm{Cl}$ and even less so for $\mathrm{X}=\mathrm{Br}$, I. Therefore, the halides can be used to generate the parent compound $13(\mathrm{R}=\mathrm{H})$ as well as the fluoride $14(\mathrm{X}=\mathrm{F}$, for $\mathrm{E}=\mathrm{S})$ (Scheme 5), at least in reaction solutions in order to measure the most relevant NMR data (Wrackmeyer, 2012; Wrackmeyer, 2014, Dalton Trans.).

Scheme 5. Synthesis of the parent compounds 13 and the fluoride 14 for NMR spectroscopy
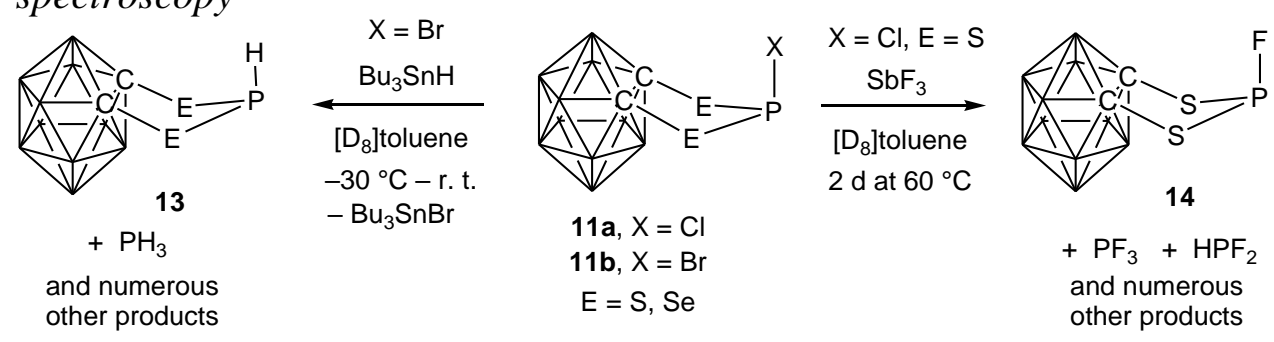

Figure 3 shows the results of some NMR spectroscopic measurements for $13(\mathrm{E}=\mathrm{S})$ as an instructive example (Wrackmeyer, 2014, Dalton Trans.). The NMR data for the corresponding $13(\mathrm{E}=\mathrm{Se})$ contain even more information, since the ${ }^{77} \mathrm{Se}$ NMR parameters are also accessible (Wrackmeyer, 2012). Of particular interest is the spin-spin coupling between ${ }^{1} \mathrm{H}(\mathrm{B}-3)$ and ${ }^{1} \mathrm{H}(\mathrm{P})$ (Fig. 2(A)), which can be regarded as a "through-space" coupling. This is not resolved in the case of $\mathbf{1 3}(\mathrm{E}=\mathrm{Se})$, most likely because of a slightly longer $\mathrm{H}^{\cdots} \mathrm{H}$ distance. We note reasonably good agreement between calculated and experimental NMR parameters (shown for example in Fig. 2(G, H) for $\delta^{11} \mathrm{~B}$ values). Calculated data were based on the optimized geometry corresponding to $\mathbf{C}$ (Fig. 1). 
Figure 3. Compound $13(E=S)$ (in [D $D_{8}$ toluene, at $23{ }^{\circ} \mathrm{C}$ ), showing long range or through-space ${ }^{1} \mathrm{H}_{-}{ }^{1} \mathrm{H}$ and ${ }^{31} \mathrm{P}_{-}{ }^{1} \mathrm{H}$ spin-spin coupling, and assignment of ${ }^{11} B$ and ${ }^{1} \mathrm{H}(\mathrm{BH}) \mathrm{NMR}$ signals. (A) $500.13 \mathrm{MHz}{ }^{1} \mathrm{H}$ NMR spectrum. (B) $500.13 \mathrm{MHz}{ }^{1} \mathrm{H}\left\{{ }^{31} \mathrm{P}\right\}$ NMR spectrum. (C) $202.5 \mathrm{MHz}{ }^{31} \mathrm{P}$ NMR spectrum. The isotope-induced chemical shift ${ }^{1} \Delta^{32 / 34} S\left({ }^{31} P\right)$ (Bjorholm, 1989) is observed. $(D)$ $202.5 \mathrm{MHz}{ }^{31} \mathrm{P}\left\{{ }^{1} \mathrm{H}\right\}$ NMR spectrum with ${ }^{1} \mathrm{H}$ broad-band decoupling. (E) 202.5 $M H z{ }^{31} P\left\{{ }^{1} H\right\}$ NMR spectrum with selective decoupling of ${ }^{1} H$ at $2.55 \mathrm{ppm} .(F)$ $500.13 \mathrm{MHz}{ }^{1} \mathrm{H}\left\{{ }^{11} \mathrm{~B}\right\} \mathrm{NMR}$ spectrum of 13 with side product (marked by asterisks), assigned by selective ${ }^{1} \mathrm{H}\left\{{ }^{11} \mathrm{~B}\right\}$ experiments. $(G) 160.5 \mathrm{MHz}{ }^{11} \mathrm{~B}\left\{{ }^{1} \mathrm{H}\right\}$ NMR spectrum of 13. (H) Stick diagram of calcd. ${ }^{11} B$ NMR signals of 13

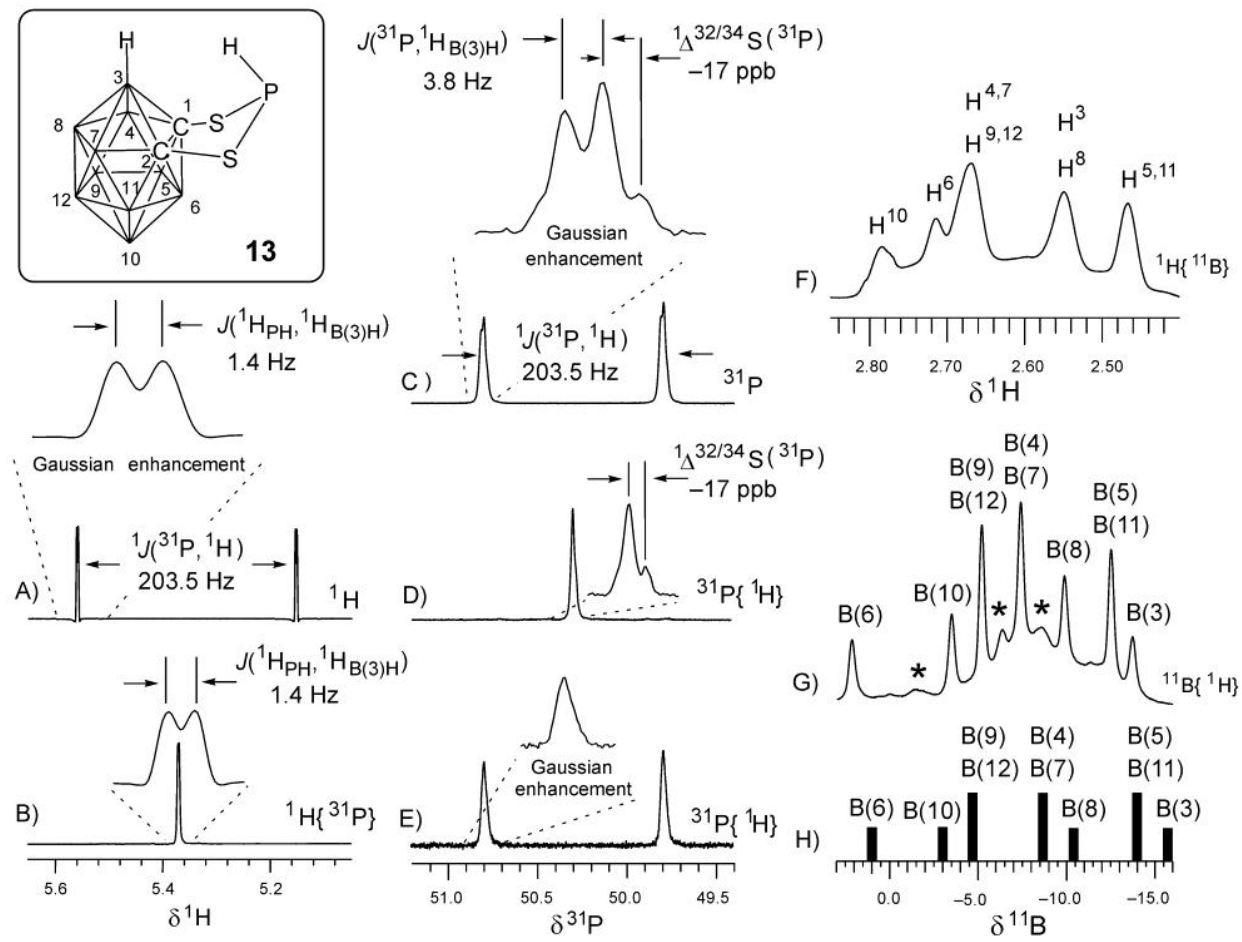

The P-organo derivatives $\mathbf{1 2 a}-\mathbf{d}$ stay as monomers in solution for a sufficient length of time to measure all important NMR parameters. Any tendency for dimerization is more pronounced for $E=S$ than for $E=S e$. Thus, for $\mathrm{R}=\mathrm{Ph}, \mathbf{1 2 d}(\mathrm{E}=\mathrm{S})$ dimerizes, whereas $\mathbf{1 2 d}(\mathrm{E}=\mathrm{Se})$ does not. By contrast, for $\mathrm{R}=t$ - $\mathrm{Bu}$ both $12 \mathrm{~b}(\mathrm{E}=\mathrm{S}, \mathrm{Se})$ dimerize readily. Also in contrast to $10 \mathrm{c}(\mathrm{E}=$ $\mathrm{O}), 12 \mathrm{c}(\mathrm{E}=\mathrm{S}, \mathrm{Se})$ do not dimerize. Similarly, dimers are not formed in the cases of the $\mathrm{P}-\mathrm{OEt}-$ and $\mathrm{P}-\mathrm{NEt}_{2}$ derivatives $\mathbf{1 2 e}, \mathbf{f}$.

In the cases of 12b with $\mathrm{R}=t$-Bu and $12 \mathrm{f}$ with $\mathrm{R}=\mathrm{NEt}_{2}$, calculations predict minima in energy for structure $\mathbf{D}(\mathrm{E}=\mathrm{S}, \mathrm{Se}$; Fig. 1$)$, and the calcd. NMR parameters are in agreement with the experimental data (Wrackmeyer, 2014, Dalton Trans.; Wrackmeyer, 2014, 1929-1948). The delicate balance between the structures $\mathbf{C}$ and $\mathbf{D}$ (Fig. 1) becomes obvious by comparing the solid-state structure of $\mathbf{1 2 d}(\mathrm{E}=\mathrm{Se})$ (Wrackmeyer, 2007), corresponding to $\mathbf{D}$, with that in solution (Wrackmeyer, 2014, 1929-1948), corresponding to C, inferred by NMR spectroscopic data and quantum-chemical analysis (Fig. 4). 
Figure 4. the solid-state structure of $\mathbf{1 2 d}$ leads to calcd. NMR parameters at drastic variance with experimental data. the latter are almost exactly reproduced by calculations based on the optimized structure shown

$$
\begin{gathered}
\text { (based on solid-state structure) } \\
{ }^{2} J\left({ }^{31} \mathrm{P},{ }^{13} \mathrm{C}_{\text {carb }}\right)=+0.9 \mathrm{~Hz} \\
{ }^{1} J\left({ }^{77} \mathrm{Se},{ }^{31} \mathrm{P}\right)=-80.7 \mathrm{~Hz}
\end{gathered}
$$

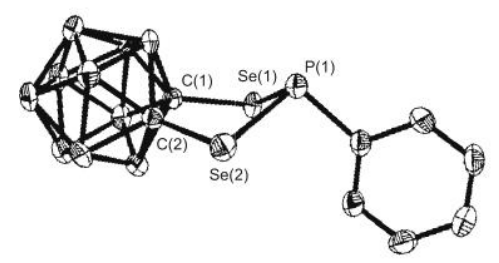

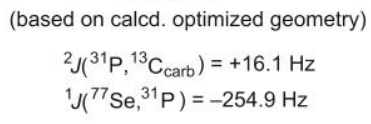

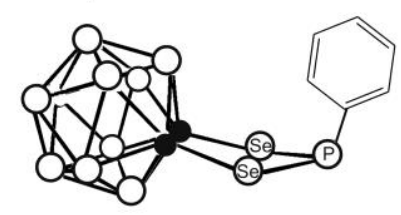

Experimental

${ }^{2} J\left({ }^{31} \mathrm{P},{ }^{13} \mathrm{C}_{\text {carb }}\right)=15.4 \mathrm{~Hz}$

${ }^{1} J\left({ }^{77} \mathrm{Se}^{31} \mathrm{P}\right)=268.2 \mathrm{~Hz}$

Figure 5. Compound $12 \mathrm{c}\left(\mathrm{E}=\mathrm{Se}\right.$ ) (in $\mathrm{CD}_{2} \mathrm{Cl}_{2}$, at $23{ }^{\circ} \mathrm{C}$ ). (A) $125.8 \mathrm{MHz}$ $\left.{ }^{13} \mathrm{C}^{1}{ }^{1} \mathrm{H}\right\}$ NMR spectrum. (B) $500.13 \mathrm{MHz}{ }^{1} \mathrm{H}\left(\mathrm{PCH}_{2}\right)$ NMR spectrum. (C) 202.5 $\mathrm{MHz} z{ }^{31} \mathrm{P}\left\{{ }^{1} \mathrm{H}\right\}$ NMR spectrum. The ${ }^{77}$ Se satellites for ${ }^{1} \mathrm{~J}\left({ }^{77} \mathrm{Se},{ }^{31} \mathrm{P}\right)$ are marked by $\nabla$. The ${ }^{13} \mathrm{C}$ satellites for ${ }^{n} \mathrm{~J}\left({ }^{31} \mathrm{P},{ }^{13} \mathrm{C}\right)(n=1,2)$ are marked by arrows; isotopeinduced chemical shifts ${ }^{n} \Delta^{12 / 13} C\left({ }^{31} P\right)(n=1,2 ; \pm 1 \mathrm{ppb})$ are given; note that the effect for $n=2$ is larger than for $n=1$. (D) $95.4 \mathrm{MHz}{ }^{77} \mathrm{Se} N \mathrm{MR}$ spectrum

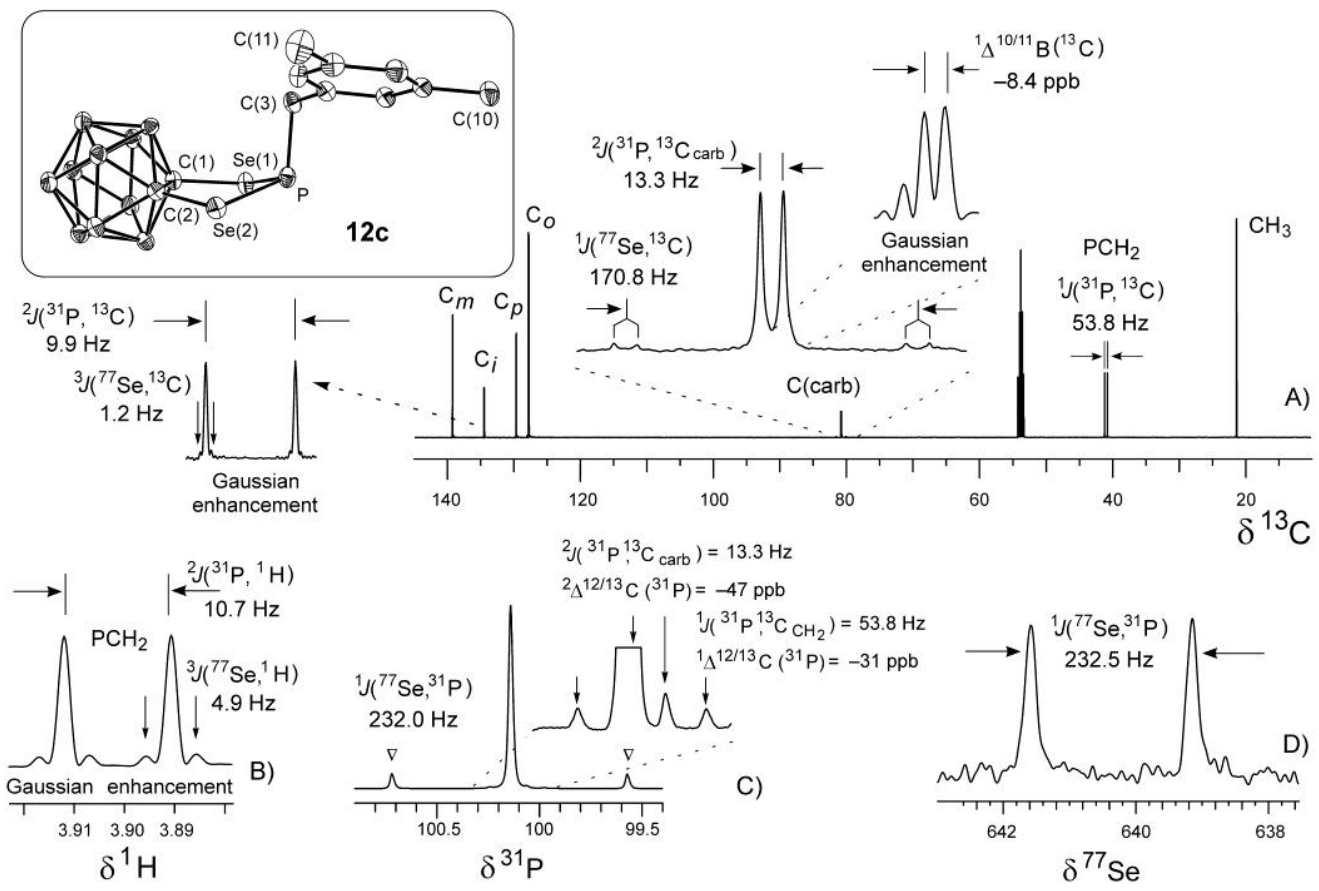

Of course, as it is frequently true, we also find that major structural features of the solid state are retained in solution, as shown for both $12 \mathrm{c}(\mathrm{E}=$ Se) and 15, for which relevant experimental NMR parameters (Fig. 5) are reproduced by calculations (Fig. 6).

The ${ }^{13} \mathrm{C}$ NMR spectrum of 12c $(\mathrm{E}=\mathrm{Se})$ [Fig. 5(A)] shows the doublet for the ${ }^{13} \mathrm{C}_{\text {carb }}$ nuclei, and the signals are further split by isotope-induced chemical shifts ${ }^{1} \Delta^{10 / 11} \mathrm{~B}\left({ }^{13} \mathrm{C}\right)$ (Wrackmeyer, 2009). An interesting observation concerns 
exceptionally large isotope-induced chemical shifts ${ }^{2} \Delta{ }^{12 / 13} \mathrm{C}_{\mathrm{carb}}\left({ }^{31} \mathrm{P}\right)=-47 \mathrm{ppb}$ (Fig. 5(C)). This appears to be a property of the five-membered ring. Isotopeinduced chemical shifts ${ }^{1} \Delta^{12 / 13} \mathrm{C}\left({ }^{31} \mathrm{P}\right)$ are known to cover a substantial range (Tattershall, 1990; Heckmann, 1999), whereas effects ${ }^{2} \Delta{ }^{12 / 13} \mathrm{C}\left({ }^{31} \mathrm{P}\right)$ are usually regarded as extremely small or negligible. We have observed the large effects ${ }^{2} \Delta^{12 / 13} \mathrm{C}_{\text {carb }}\left({ }^{31} \mathrm{P}\right)$ for all 1,3-dichalcogeno-2-phospholanes studied here for $\mathrm{E}=\mathrm{S}$, Se, Te (Wrackmeyer, 2014, 1929-1948).

Figure 6. ${ }^{31} \mathrm{P}$ and ${ }^{77} \mathrm{Se}$ NMR Spectra of 15. Relevant coupling constants have to be extracted by Simulation of the Complex Experimental Spectra using the Spin Systems as shown

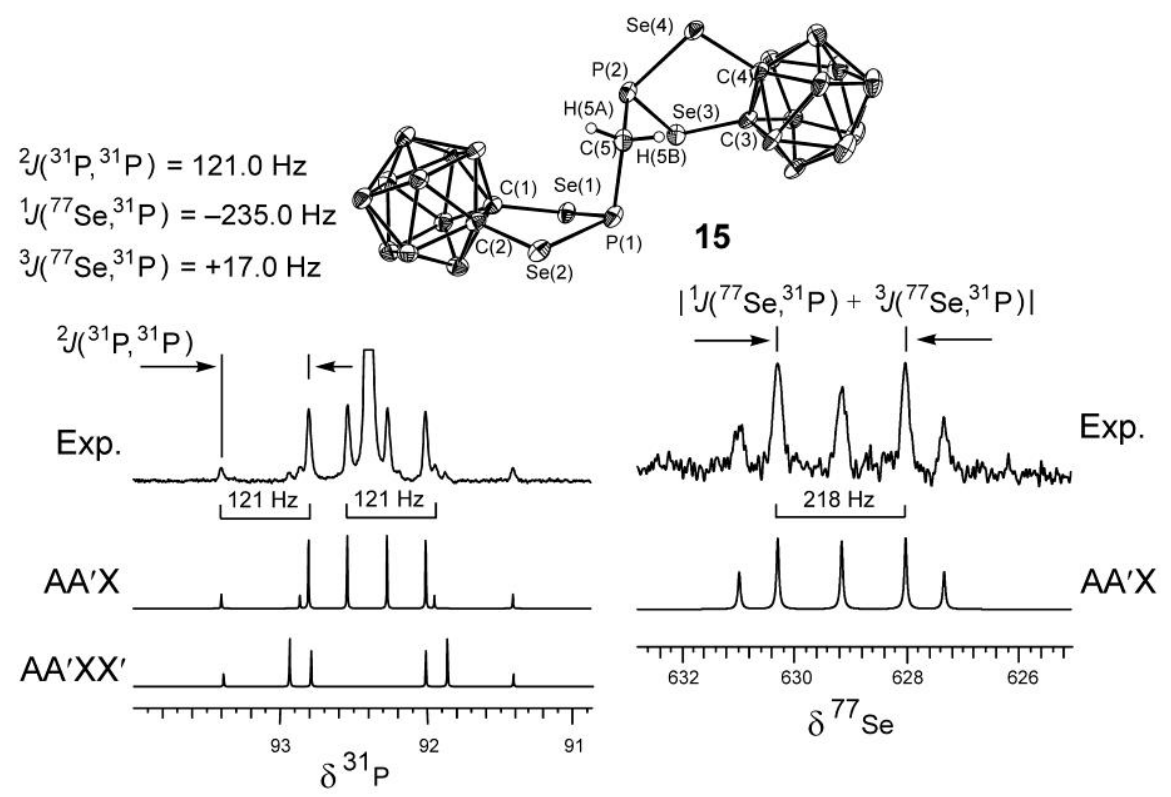

There are notable differences between the sulfur and selenium compounds studied here. Thus, the $\mathrm{P}-\mathrm{Se}$ bonds are more reactive than the $\mathrm{P}-\mathrm{S}$ bonds, as shown by oxidative additions (Wrackmeyer, 2007). Even the apparently simple addition of selenium to prepare phosphorus selenides (e.g. 16a) turned out to be accompanied by insertion of selenium into the $\mathrm{P}-\mathrm{Se}$ bonds (17a) (Scheme $6)$. With the $i$-Pr group $(\mathrm{E}=\mathrm{Se} ; \mathbf{1 2 a})$ a single isomer is formed, whereas two isomers 17d are observed for $\mathrm{R}=\mathrm{Ph}$, starting from 12d (Wrackmeyer, 2013, 140-147). Again, a single isomer 17c is formed starting from 12c (Wrackmeyer, 2014, 1929-1948). The solid-state structure of 17a could be characterized by X-ray structural analysis (Fig.7), and its formation was conveniently monitored by ${ }^{31} \mathrm{P}$ and ${ }^{77} \mathrm{Se} \mathrm{NMR}$ spectroscopy (Fig. 8) (Wrackmeyer, 2013, 140-147). 
Scheme 6. Reaction of 12 a with selenium via the expected 16a towards 17 a

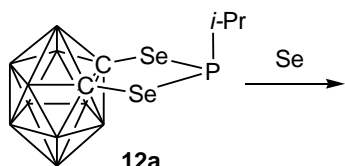

$12 a$
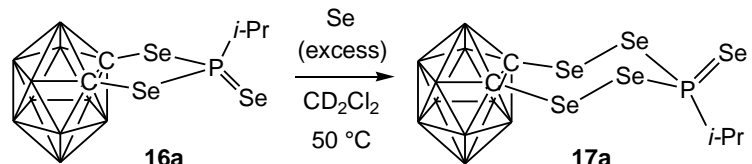

Figure 7. ORTEP plot (50\% probability; hydrogen atoms are omitted for clarity) of the molecular structure of 17a. Selected bond lengths (pm) and angles ( $\left.{ }^{\circ}\right): C 1-C 2$ 171.1(1), C1-Se1 194.6(1), Se1-Se3 231.1(2), Se3-P 225.1(3), P-Se5 207.4(4), P-C3 184.4(1); Se3-P-Se4 111.4(1)

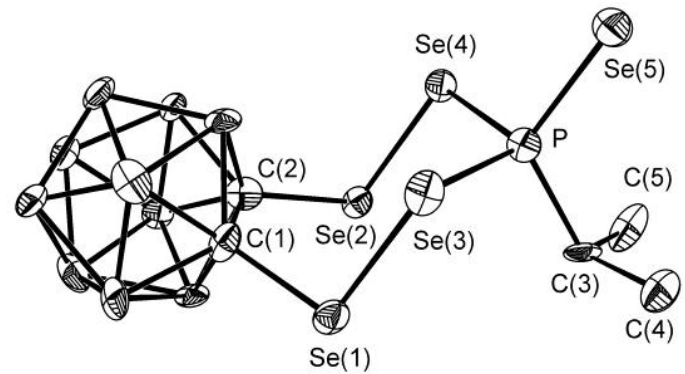

Figure 8. NMR Spectra of the Reaction solution obtained from the reaction of $12 a$ with Se (Scheme 6). Upper Trace: $202.5 \mathrm{MHz}{ }^{31} \mathrm{P}\left\{{ }^{1} \mathrm{H}\right\}$ NMR spectrum after 24 h at $55{ }^{\circ} \mathrm{C}$ in $\mathrm{CD}_{2} \mathrm{Cl}_{2}$, the mixture of $16 \boldsymbol{a}$ and $17 \mathrm{a} ;{ }^{77} \mathrm{Se}$ satellites are marked by arrows. Lower trace: $95.4 \mathrm{MHz}{ }^{77} \mathrm{Se} N \mathrm{MR}$ spectrum of the same mixture

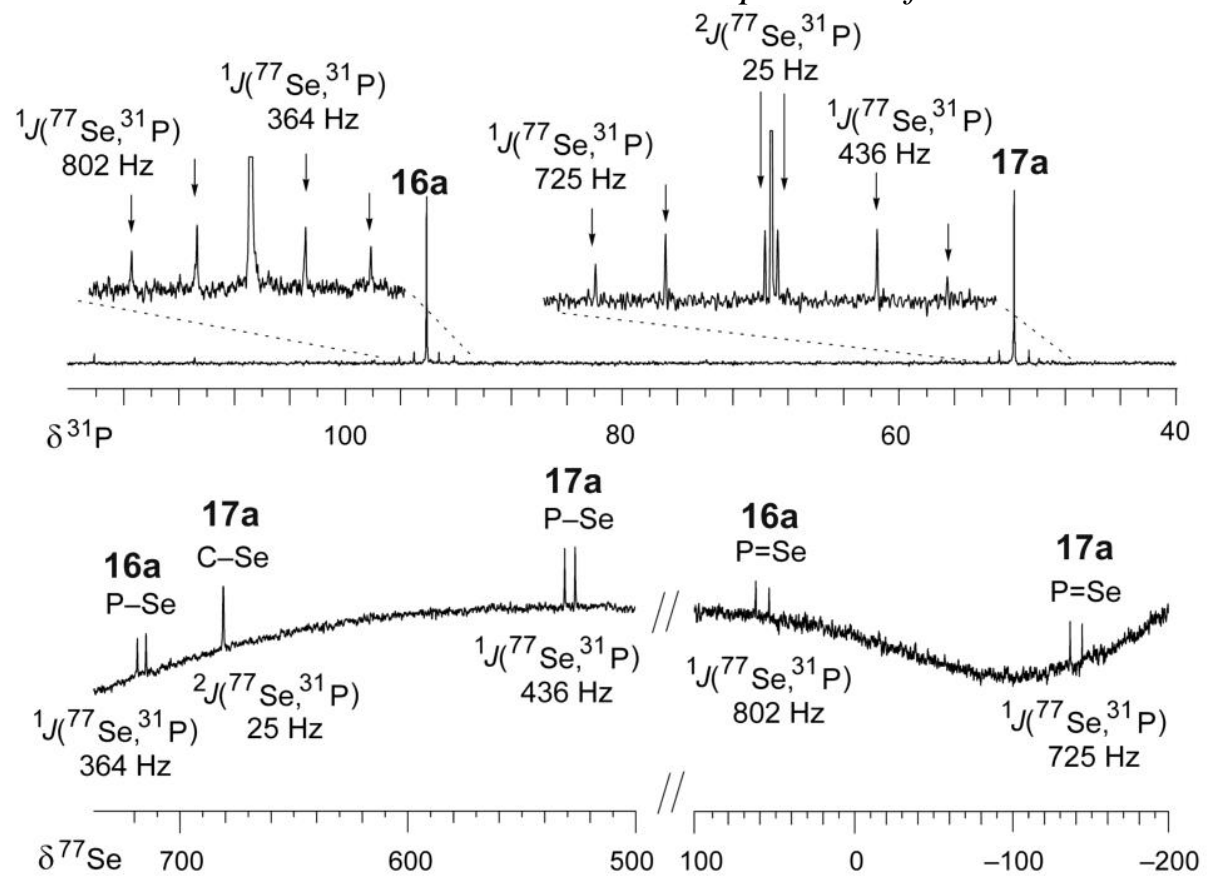




\section{1,3-Ditellura-2-phospholanes with an annelated 1,2-dicarba-closo-} dodecaborane (12) Unit

Since the silane with $\mathrm{E}=\mathrm{Te}$ analogous to $\mathbf{6}$ is not accessible so far (Wrackmeyer, 2013, 398-408), the di-lithium salt $3(\mathrm{E}=\mathrm{Te})$ is used in reactions with phosphorus halides (Scheme 7). Problems are encountered because the nature of $\mathbf{3}$ depends in an unpredictable way on experimental conditions (Herberhold, 2006; Wrackmeyer, 2013, 398-408). Therefore, the desired products $\mathbf{1 8}$ are formed in the presence of numerous side-products, readily shown by ${ }^{31} \mathrm{P}$ and ${ }^{125} \mathrm{Te}$ NMR spectroscopy, which are difficult to separate (Wrackmeyer, 2014, 1929-1948). NMR data indicate that, except of 18e, all others adopt the structure of type $\mathbf{C}$ (Fig. 1), even $\mathbf{1 8 b}$, for which the sulfur and selenium analogues (12b) prefer D (Fig.1). The 1,3-ditellura-2phospholanes 18 do not dimerize. In constrast to their analogues with $\mathrm{E}=\mathrm{O}, \mathrm{S}$, Se, compounds $\mathbf{1 8}$ are light-sensitive in solution as well as in the solid state.

Scheme 7. Synthesis of 1,3-ditellura-2-phospholanes
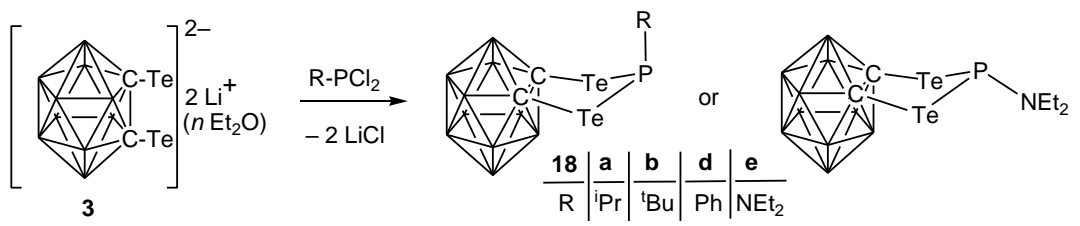

\section{Conclusions}

In principle, 1,3-dichalcogeno-2-phospholanes with an annelated 1,2dicarba-closo-dodecaborane(12) unit are accessible taking advantage of the availability of starting materials shown in Scheme 1 and their reactions with phosphorus halides. The annelated rigid three-dimensional carborane skeleton causes repulsive interactions either with the substituent at phosphorus or with the electron density of the lone pair of electrons at phosphorus, depending on the respective structure ( $\mathbf{C}$ or $\mathbf{D}$; Fig. 1). This destabilizes the five-membered rings, in particular if $\mathrm{E}-\mathrm{P}$ and $\mathrm{E}-\mathrm{C}_{\text {carb }}$ distances are short, as for $\mathrm{E}=\mathrm{O}$, and for many $\mathrm{P}$-organo derivatives, even for $\mathrm{E}=\mathrm{S}$ and $\mathrm{E}=\mathrm{Se}$, dimerization is the way out. All dimers studied so far possess analogous structures, in which the four chalcogen atoms are in one plane leaving room for the complexation or even encapsulating of various cations. It was shown that multinuclear magnetic resonance methods $\left({ }^{1} \mathrm{H},{ }^{11} \mathrm{~B},{ }^{13} \mathrm{C},{ }^{31} \mathrm{P},{ }^{77} \mathrm{Se}\right.$ and ${ }^{125} \mathrm{Te}$ NMR spectroscopy) together with quantum-chemical analyses were suitable to unravel the solutionstate structures which sometimes were found to be at variance with those in the solid state.

\section{Acknowledgement}

Support of this work by the Deutsche Forschungsgemeinschaft is gratefully acknowledged. 


\section{References}

Albrand, J.-P., Gagnaire, D., Martin, J. and Robert, J.-B. 1973. Etude par Résonance Magnétique Nucléaire de dérivés phosphores. Etude de dithiaphospholanes-1,3,2. Org. Magn. Reson. 5, (1), 33-41; and references cited therein.

Arbuzov, A. E., Zoroastrova, V. M. and Rizpolozhenskii, N. I. 1948. Preparation and properties of some cyclic esters of phosphorous acid. Izv. AN SSSR. Ser. khim. 208-218 [In Russian].

Arbuzov, A. E. and Zoroastrova, V. M. 1952. Ethylene ester of phosphorochloridodithious acid, and related substances. Bull. Acad. Sci. USSR. Div. Chem. Sci. 1, 437-441 (Engl. Transl.).

Becke, A. D. 1993. Density-functional thermochemistry. III. The role of exact exchange. J. Chem. Phys. 98, (7), 5648-5652.

Bjorholm, T. and Larsson, F. C. V. 1989. ${ }^{34}$ S Isotope Effects on ${ }^{31} \mathrm{P}$ Chemical Shifts in Thiophosphate Esters. Magn. Reson. Chem. 27, 184-186.

Bregadze, V. I. 1992. Dicarba-closo-dodecaboranes $\mathrm{C}_{2} \mathrm{~B}_{10} \mathrm{H}_{12}$ and their derivatives. Chem. Rev. 92, 209-223.

Burg, A. B. and Griffiths, J. E. 1961. The acid $\mathrm{CF}_{3} \mathrm{PO}_{2} \mathrm{H}_{2}$, its ester, association and structure. J. Am. Chem. Soc. 83, 4333-4337.

Contreras, R. H., Barone, V., Facelli, J. C. and Peralta, J. E. 2003. Advances in Theoretical and Physical Aspects of Spin-Spin Coupling Constants. Annu. Rep. NMR Spectrosc. 51, 167-260.

Dutasta, J. P., Martin, J. and Robert, J. B. 1980. Phosphonites cycliques, oligomerisation, obtention de macrocycles phosphores. Etude R.M.N. et stereochimique. Heterocycles 14, 1631-1648.

Fontal, B. and Goldwhite, H. 1966. Configurational stability in some 3-coordinate phosphorus compounds. Tetrahedron 22, (10), 3275-3278.

Grimes, R. N. 2011. Carboranes. 2nd ed. New York, Academic Press.

Heckmann, G., Becker, G. and Kraft, H. 1999. Extremely large one-bond ${ }^{31} \mathrm{P}^{13} \mathrm{C}$ and two-bond ${ }^{31} \mathrm{P}^{18} \mathrm{O}$ isotope shifts in $\left[\left(\mathrm{H}_{3} \mathrm{C}\right)_{2} \mathrm{CH}\right]_{3} \mathrm{Si}-\mathrm{O}-\mathrm{C} \mathrm{P}$, a new representative of $\lambda 3$-phosphaalkynes, and isotope shifts of several derivatives and some $\lambda 3$ phosphaalkenes. Magn. Reson. Chem. 37, 667-671.

Helgaker, T., Jaszunski, M. and Pecul, M. 2008. The quantum-chemical calculation of NMR indirect spin-spin coupling constants. Progr. NMR Spectrosc. 53, 249-268.

Herberhold, M., Jin, G.-X., Yan, H., Milius, W. and Wrackmeyer, B. 1999. 16- and 18-Electron $\mathrm{Cp} * \mathrm{Rh}$ complexes with 1,2-dicarba-closo-dodecaborane(12)-1,2dichalcogenolato ligands, as studied by multinuclear magnetic resonance. $J$. Organomet. Chem. 587, 252-257.

Herberhold, M., Milius, W., Jin, G.-X., Kremnitz, W. and Wrackmeyer, B. 2006. Molecular Structures of some Tellurium Derivatives of 1,2-Dicarbaclosododecaborane(12). Z. Anorg. Allg. Chem. 632, 2031-2036.

Jin, G.-X. 2004. Advances in the chemistry of organometallic complexes with 1,2dichalcogenolato-o-carborane ligands. Coord. Chem. Rev. 248, 587-602.

Krishnan, R., Blinkley, J. S., Seeger, R. and Pople, J. A. 1980. Selfconsistent molecular orbital methods. XX. A basis set for correlated wave functions. $J$. Chem. Phys. 72, (1), 650-654.

Lee, C., Yang, W. and Parr, R. G. 1988. Development of the Colic-Salvetti correlation-energy formula into a functional of the electron density. Phys. Rev. B $37,(2), 785-789$. 
Lucas, H. J., Mitchell, F. W., Jr. and Scully, C. N. 1950. Cyclic phosphites of some aliphatic glycols. J. Am. Chem. Soc. 72, 5491-5497.

McLean, D. and Chandler, D. G. S. 1980. Contracted Gaussian basis sets for molecular calculations. I. Second row atoms, $\mathrm{Z}=11-18$. J. Chem. Phys. 72, (10), $5639-5648$.

Ogawa, S., Saito, M., Ogasawara, M. and Sato, R. 1995. Preparation and multi-nuclear NMR study of new benzodichalcogenaphospholes. Heterocycles 41, 5, 889-892.

Ohta, K., Goto, T., Yamazaki, H., Pichierri, F. and Endo, Y. 2007. Facile and Efficient Synthesis of $C$-Hydroxycarboranes and $C, C^{\prime}$-Dihydroxycarboranes. Inorg. Chem. 46, 3966-3970.

Popescu, A. R., Musteti, A. D., Ferrer-Ugalde, A., Viñas, C., Núñez, R. and Teixidor, F. 2012. Influential Role of Ethereal Solvent on Organolithium Compounds: The Case of Carboranyllithium. Chem. Eur. J. 18, 3174-3184.

Peake, S. C., Fild, M., Schmutzler, R., Harris, R. K., Nichols, J. M. and Rees, R. G. 1972. Preparation and nuclear magnetic resonance spectral analysis of 1,3,2dithiaphospholanes. J. Chem. Soc., Perkin Trans. 2 (4), 380-385.

Pudovik, M. A., Ovchinnikov, V. V., Cherkasov, R. A. and Pudovik, A. N. 1983. The reactivity of 1,3,2-diheterophospholans containing a tricoordinate phosphorus atom. Russ. Chem. Rev. 52, (4), 361-376.

Smith, H. D., Jr., Obenland, C. O. and Papetti, S. 1966. A New Series of Organoboranes. IX. The Preparation and Some Reactions of Sulfur-Carborane Derivatives. Inorg. Chem. 5, 1013-1015.

Stevens, P. J., Devlin, F. J., Chablowski, C. F. and Frisch, M. J. 1994. Ab Initio Calculation of Vibrational Absorption and Circular Dichroism Spectra Using Density Functional Force Fields. J. Phys. Chem. 98, (45), 11623-11627.

Tattershall, B. W. 1990. Phosphorus-carbon nuclear magnetic coupling constants in phosphorus(III) cyanides. Polyhedron 9, 553-555.

van Wüllen, W. 2000. A comparison of density functional methods for the calculation of phosphorus-31 NMR chemical shifts. Phys. Chem. Chem. Phys. 2, 2137-2144.

Wieber, M., Otto, J. and Schmidt, M. 1964. Condensation of methyldichlorophosphine with dithiols. Angew. Chem. 76, (14), 648.

Wollinski, K., Hinton, J. F. and Pulay, P. J. 1990. Efficient Implementation of the Gauge-Independent Atomic Orbital Method for NMR Chemical Shift Calculations. J. Am. Chem. Soc. 112, 8251-8260.

Wrackmeyer, B., García Hernández, Z., Kempe, R. and Herberhold, M. 2007. 1,3,2Diselenaphospholanes with an annelated dicarba-closo-dodecaborane(12) unit. $Z$. Anorg. Allg. Chem. 633, 851-857.

Wrackmeyer, B., García Hernández, Z., Lang, J. and Tok, O. L. 2009. 1,2-, 1,7- and 1,12-Dicarba-closo-dodecaborane(12) Derivatives Revisited by ${ }^{13} \mathrm{C}$ NMR Spectroscopy and DFT Calculations. First Observation of Isotope-Induced Chemical Shifts ${ }^{1} \Delta^{10 / 11} \mathrm{~B}\left({ }^{13} \mathrm{C}\right)$, and the Signs and Magnitudes of Coupling Constants ${ }^{1} J\left({ }^{13} \mathrm{C},{ }^{13} \mathrm{C}\right)$ and ${ }^{1} J\left({ }^{13} \mathrm{C},{ }^{11} \mathrm{~B}\right)$. Z. Anorg. Allg. Chem. 635, 1087-1093.

Wrackmeyer, B., Klimkina, E. V. and Milius, W. 2010. Synthesis and reactivity of some diselenasila cycles containing an annelated dicarba-closo-dodecaborane(12) unit. Appl. Organomet. Chem. 24, 25-32.

Wrackmeyer, B., Klimkina, E. V. and Milius, W. 2012. 2-Halogeno-1,3,2diselenaphospholanes with an Annelated Dicarba-closo-dodecaborane(12) Unit. Synthesis, Molecular Structure and Reactivity. Eur. J. Inorg. Chem. 2908-2915.

Wrackmeyer, B., Klimkina, E. V. and Milius, W. 2013. Synthesis of some Tellurasila Cycles Containing an Annelated Dicarba-closo-dodecaborane(12) Unit. Structure 
of a 1,4-Ditellura-2,3-disila-cyclohexane Derivative. Eur. J. Inorg. Chem. 398408.

Wrackmeyer, B., Klimkina, E. V. and Milius, W. 2013. Oxidation of 1,3,2Diselenaphospholanes with an Annelated Dicarba-closo-dodecaborane(12) Unit by Addition of Sulfur and Selenium. Molecular Structure of a Novel 1,2,4,5Tetraselena-3-phospha Heterocycle. J. Organomet. Chem. 747, 140-147.

Wrackmeyer, B., Klimkina, E. V. and Milius, W. 2014. 1,3,2-Dioxaphospholanes with an annelated 1,2-dicarba-closo-dodecaborane(12) unit: Formation and dimerization. Eur. J. Inorg. Chem. 233-246.

Wrackmeyer, B., Klimkina, E. V. and Milius, W. 2014. 1,3,2-Dithiaphospholanes with an annelated 1,2-dicarba-closo-dodecaborane(12) unit: Formation and reactivity. Dalton Trans. 43, 5021-5043.

Wrackmeyer, B., Klimkina, E. V. and Milius, W. 2014. 1,3,2-Diselena- and 1,3,2ditelluraphospholanes with an annelated 1,2-dicarba-closo-dodecaborane(12) unit. Eur. J. Inorg. Chem., 1929-1948. 
